\title{
The Concept of Rationality in Neoclassical and Behavioural Economic Theory
}

\author{
Alexandr Soukup ${ }^{1}$, Mansoor Maitah ${ }^{2} \&$ Roman Svoboda ${ }^{1}$ \\ ${ }^{1}$ Department of Economic theories, Faculty of Economics and Management, Czech University of Life Sciences \\ Prague, Czech Republic \\ ${ }^{2}$ Department of Economics, Faculty of Economics and Management, Czech University of Life Sciences Prague, \\ Czech Republic \\ Correspondence: Alexandr Soukup, Faculty of Economics and Management, Czech University of Life Sciences \\ Prague, Kamycka 129, Prague 6 16921, Czech Rep. E-mail: soukupa@pef.czu.cz
}

Received: September 16, $2014 \quad$ Accepted: October 16, $2014 \quad$ Online Published: November 27, 2014

doi:10.5539/mas.v9n3p1 URL: http://dx.doi.org/10.5539/mas.v9n3p1

\begin{abstract}
Theories that are based on the neoclassical basis such as expected utility theory or the theory of efficient markets assume rational choice of subjects in the sense of an optimal choice according to the criteria of neo-classical economics. Behavioral theory such as prospect theory assumes limited rationality in the choice of subjects. In this research the problem of choosing subjects is treated differently. The aim of this paper is to attempt a comparison between two basic approaches of contemporary economic theories that are applied in the financial markets, but also in other spheres of economic activity (public economics).
\end{abstract}

Keywords: expected utility theory, behavioral theory, prospect theory, limited rationality, heuristics

\section{Introduction}

Economic theory has been developing for centuries and a number of different schools of thought have taken turns in it. Each of them has its pros and cons. In fact, many new streams have their predecessors or roots in the past.

J. Schumpeter (Schumpeter, 1994) detects the basics of a model, which is called homo economicus, in the later Scholastics. For example, Antonín Florence (1389-1459) uses the phrase "economic activity diligence" and Bartolomeo Frigerio wrote in 1629 a treatise titled "L'economo Prudente" in which, according to Schumpeter, we find a mention of the rationality of human behavior.

The neoclassical theory developed its concept of a rationally acting entity within the concept of homo economicus, as early as the 19th century. This notion was further developed, for example, within the concept of expected utility.

From approximately the mid-20th century new knowledge begins to emerge of the cognitive processes and of the implementation of human choice in other sciences as well, especially in psychology. A later trend also shows penetration of psychology into economics. Amongst other things this has led to the emergence of behavioral economics. Very important for its creation were the works of H. Simon, whose concept was later developed by D. Kahneman and A. Tversky. According to these authors, a rational analysis of an entity is influenced by other factors which may completely reverse its result in some cases.

In addition to the well-known Robbins's definition of economics as a science of personal choice between different alternatives according to the criteria of net gains under the conditions of full awareness, there is also, for example, Keynes's alternative definition that states the following:

"Economics is the ability to think within the framework of models defined by different conditions associated with the art of choosing models that have proved their worth under the conditions of the contemporary world" (Colander, 2000).

Keynes's definition emphasizes the ability to think, therefore, the meaning of a certain type of economic rationality. 


\section{Aim and Methodology}

The aim of this paper is to attempt a comparison between two basic approaches of contemporary economic theories. These are concepts stemming partly from the neoclassical approach, and partly from behavioral theories that have recently become much more visible. Both approaches differ mainly in the general concept of rationality. It is also important to highlight the role of H. Simon in the development of the later concepts by D. Kahneman and A. Tversky, the most important theoreticians of behavioral economics.

The behavioral theory (e.g. prospect theory) is based on the assumption of bounded rationality. Due to its expectations, the attention is paid to the concept of rational choice and the issue of bounded rationality, which was first outlined by H. Simon as early as the 1950's of the 20th century. Its exploration was further refined by D. Kahneman and A. Tversky in the 1970's and they continued to do so even later. We characterize and compare the two approaches, particularly the methods of the findings evaluation and making a selection in two basic theories.

\section{Rationality in Economic Theory, the Neoclassical Approach}

In neoclassical theory the concept of rationality is associated with maximizing net revenue, for example, a total gain. Entities thus act on the basis of their preferences which are given exogenously, whatever they may be. The characteristics of their behavior are thus inferred from the concept of benefits and preferences. The preferences are abstracted from the cultural and social framework and the maximizing entity is understood to be lonely yet having perfect information and the ability of logical calculation. A model of a perfectly calculating and selfish entity is suitable for mathematical modelling.

Theoreticians of this stream (e.g. M. Friedman) state that it is clear how unrealistic these assumptions are. However, the aim is not to describe but to predict. While it is true that functional predictions will arise on the basis of these assumptions and the theoretical framework, there is no reason why these assumptions should change. It depends on the ability of the model to generate adequate predictions. This is a well-known theory of "as if". Furthermore, institutional economics emerged in response to the illusory assumption of an isolation of the entities.

In order to compare both great concepts, it is first necessary to clearly formulate assumptions of the neoclassical model.

\subsection{Assumptions of the Neoclassical Concept of Rational Behavior of an Entity}

1) The entity makes a choice from a closed set of given and known alternatives (admissible set)

2) The entity knows all the relevant information for each alternative

3) The entity's preferences are given exogenously and they are complete, transitive and stable

4) The entity's utility function is clearly given mainly by its preferences

5) The entity maximizes the expected utility and minimizes the costs with respect to various constraints (as if resolving a task of looking for a bound extreme of a function of expected utility in an admissible set)

6) Selection of an entity is not dependent on the framing of the problem (including prejudices, superstitions, etc.)

7) The principle of methodological individualism (the individual is the sole entity of decision making)

8) The principle of methodological positivism (the ability of a model to generate adequate predictions is the sole criterion of its correctness)

The main assumption of the model is an entity making decisions that is perfectly informed about all choice alternatives, is aware of its limitations and due to these limitations is looking for the best possible choice of means to achieve the goals.

John von Neumann and Oskar von Morgenstern are the authors of the theory of expected utility. The theory of expected utility has earned a respected position in neoclassical economic theory and in this work we consider it as standard. It is based on the concept of rational behavior in the neoclassical approach and it, therefore, contrasts with the prospect theory, which is described below.

The key idea of this theory is that people make decisions according to two principles. The first principle is a measure of utility which flow from the selected alternative and the second is the probability of this alternative happening.

The theory of expected utility has earned a respected position in neoclassical economic theory and in this work we consider it as its standard part. 
Preconditions for making a choice in the theory of expected utility are as follows:

1) A correctly defined function of the total utility of an entity that is making a decision

2) It is possible to express the total utility level for future situations as well

3) The entity knows the subjective distribution of the probabilities of each alternative's results

4) The choice is performed on a closed set of the given and known alternatives

5) The aim of the choice is to maximize the expected values of a given function of the total utility

This concept of rationality in neoclassical theory was summed up by M. Blaug (1992) as follows: "Rationality is a choice in harmony with the preferential arrangement that is complete and transitive, under conditions of perfect and cost-free awareness; where an uncertainty of future results occurs, the rationality means maximizing expected utility, which is a utility multiplied by the probability of the occurrence of a given outcome " (Blaug, 1992).

According to Blaug, neo-classical economists also assume a preference for a greater quantity to a smaller one, a choice of an investment with the highest rate of return, cost minimization, and the pursuit of self-interest, regardless of the welfare of others, as the main principle of human behavior.

\subsection{The Roots of Behavioral Approaches in the Previous Economic Theory}

Smith, in his work titled The Theory of Moral Sentiments stated this: "It has already been observed that we suffer more, when we fall from a better to a worse situation, than we ever enjoy when we rise from a worse to a better. Security, therefore, is the first and the principal object of prudence. It is averse to expose our health, our fortune, our rank, or reputation to any sort of hazard" (Smith, 2005).

This concept is developed by Kahneman's value function that is concave in the gains band and convex in the losses band.

Similar considerations can also be found in the concept of utility. According to W. Jevons, utility resulting from a certain event is also affected by the intensity and duration of the event. F. Edgeworth (Edgeworth, 1967) formulated a utility function based on his concept and called it the law of adaptation. According to this function, the utility does not depend only on the current consumption, but also the past. Later, this idea appears with D. Kahneman.

\section{Simon's Concept of Bounded Rationality}

The concept of bounded rationality was first used H. Simon (Simon, 1955), when he stated that people do not always behave as rationally acting beings within the concepts of rational behavior models, including the neo-classical.

According to Simon, bounded rationality is a result of the existence of two types of reasoning. The first is intuitive, unconscious and makes conclusions more quickly; the second is rational, functions according to the principles of logical thinking and works more slowly. The thinking process, as a whole, integrates both types.

These two types of thinking can sometimes complement each other, but at other times the intuitive type modifies the results of the second. Therefore, errors in reasoning or mental shortcuts do not show in every situation, but only in some.

This idea was later elaborated by D. Kahneman and A. Tversky. On the basis of these two types of thinking D. Kahneman developed in his last work his concept of the System 1 and System 2 of human thinking (Kahneman, 2012).

Simon's main idea is that in practical dealings people do not seek an optimal solution of the choice they are facing, but are content with the first satisfactory solution, specifically with the first solution that appears to them to be satisfactory. At the same time, it is true that the criteria for the level of this satisfaction depend on their subjective view of the problem being resolved. Entities do not perform a deep analysis of whether their view is adequate. Individuals do not always examine the incomes and expenses of their operations. After achieving an acceptable threshold of satisfaction they proceed towards the next choice (Simon, 1955).

1) Entities may not know all the possible consequences of all alternatives of their actions

2) Entities have a limited imagination regarding the future development of their own values

3) Entities cannot even imagine all the possible alternatives of their actions

Thus there are two factors that restrict the ability to create a stable and orderly system of preferences, which 
assumes the neoclassical concept of rationality. They deal with, firstly, a limited ability to calculate, which concerns the biological characteristics of an individual and, secondly, a limited amount of information that the subject is capable of acquiring, which implies imperfect awareness. The Simon's concept of bounded rationality was formed on the basis of these two factors.

This, therefore, means that intellectual capabilities of acting entities in solving complex problems are considerably limited. "Rational" dealing is thus based on extremely simplified patterns that respect only some features of given problems. This corresponds to the final solution.

According to Simon the entities make their decisions in the following manner: If a relevant alternative would bring less profit (net income) than would correspond with the expectations of an individual, it would not be carried out. If it does go ahead, it is carried out even if it is not the best achievable alternative. Simon calls this expected level an aspiration level $\mathrm{V}=0$ (Simon, 1955). The aspiration level is formed on the basis of past experience or expectations of profit from the available alternatives (Figure 1).

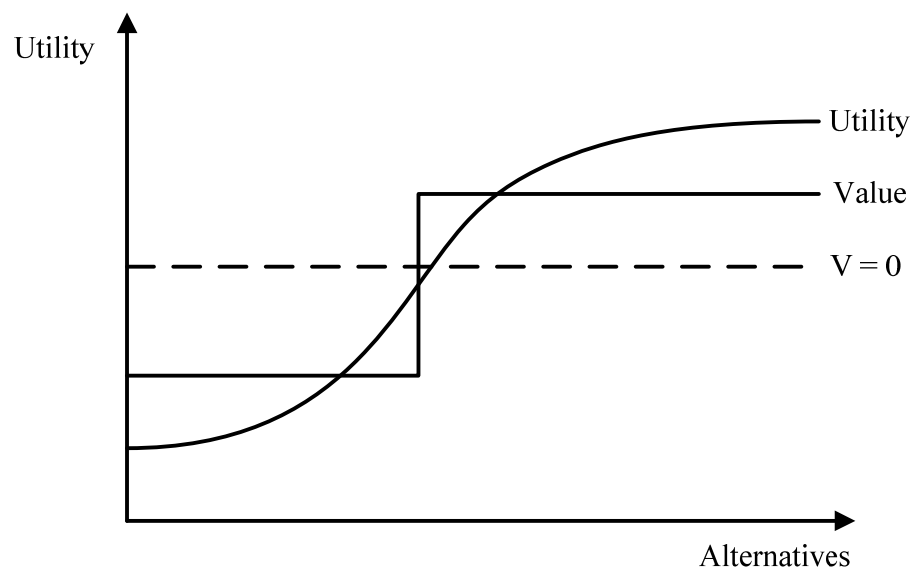

Figure 1. The utility function and the function of satisfaction (Simon, 1955)

The number and quality of pieces of information determine whether a relevant alternative would be selected. Alternatives are often compared only in some aspects or in just one. Simon also believes that even repetition of given situations will not lead to the entity acting rationally because their behavior is always influenced by the environment. This adaptation leads to a behavior which can then be called adaptive rationality.

Simon (Simon, 1996) in his investigation further distinguished between the substantive and procedural rationality. Substantive rationality is manifested by an adaptation to the external environment and is limited by knowledge and skills of the entity. Procedural rationality leads to the discovery of appropriate adaptive behavior.

The neoclassical theory assumes substantive rationality. That depends on the preferences of a entity which possesses perfect (one hundred percent) awareness and from a given set of alternatives chooses the one that brings him/her the highest expected utility. This type of rationality is focused only on results.

According to Simon (Simon, 1996) the substantive rationality occurs only in those choices by the entity, which are simple and well structured. However, if the problem of choice is more complex, the entities are satisfied with sufficient (imperfect) information, they will simplify their decisions, and select a satisfactory (but not optimal) solution. This procedural rationality does not include a possibility of prediction.

If we wanted to modify the above assumptions of the expected utility theory according to Simon's concept of bounded rationality, it would probably look something like this:

1) Well-defined functions of the total utility with the exception of cardinality

2) It is possible to estimate the overall utility of some of the available alternatives

3) The set of alternatives is not constant, the entity is more likely to produce possible choices (based on Hayek's concept of the functioning of the human mind)

4) Creating subjective estimates, which does not necessarily imply knowledge of probability 
5) Strategies of making decisions which lead to a satisfactory result

According to Simon (Simon, 1983) the neoclassical model "... perhaps serve as a model of the mind of God, but certainly not as a model of the mind of man."

For his contribution in the field of exploration of bounded rationality H. Simon was awarded the Nobel Prize in 1978. D. Kahneman and A. Tversky followed up in this research.

\section{Bounded Rationality According to Kahneman and Tversky}

\subsection{Development}

In general, D. Kahneman and A. Tversky are considered the founders of behavioral economics. The predecessor of the concept was H. Simon, who had previously reached similar conclusions, but created only a theoretical mathematical model without experiments. Kahneman and Tversky conducted many experiments to support their theoretical concepts.

They published the first results in 1974 in their paper on decision making under conditions of uncertainty (Kahneman and Tversky, 1974). In the paper, Kahneman and Tversky described the three basic heuristics (representativeness, availability and anchor), which lead to the fact that entities deviate from normal behavior based on common rationality expected by neoclassical model.

The authors also continued with Simon's idea of two methods of reasoning, which they called System 1 and System 2. The Rational System 2 modifies the results of the System 1 only in some cases. Errors in judgment are therefore manifested only sometimes.

According to both authors, the alternative theory of decision making, which has been called by Kahneman and Tversky a descriptive theory of preferences, takes into account the fact that people do not evaluate probabilities linearly. They perform the weighing of objective probabilities, and thus give them a subjective importance, which the authors justify with the use of psychology. This weighing of probabilities is associated with the theory of expected utility which, in this modified form, could then be also applied to areas that the original theory found difficult to explain (Tversky and Kahneman, 1979).

This paper laid the foundations of the prospect theory which was later successfully applied, for example in the analysis of the assets market. By the end of the 1970's it was further developed by R. Thaler (Thaler, 1980). The role of heuristics in decision-making was elaborated by the authors in papers published in the 1980's (Kahneman and Tversky, 1981).

The prospect theory was further developed by the authors in the paper published in 1992 (Tversky and Kahneman, 1992). Here the authors characterize the value function in detail. This function is concave in the profit area and convex in losses. According to empirical research, the slope of the value function is $2-2.5$ times steeper in losses. This means that entities evaluate the pain of losing as $2-2.5$ times more intense than the pleasure from gain which is of the same size in absolute value. The break point is in the reference point.

According to the prospect theory there are two stages in the choice process:

1) The initial phase, which involves reasoning and simplification (editing)

2) The subsequent phase, which includes an evaluation and a choice between alternatives (evaluation)

The task of the first phase is to simplify and reformulate a given problem of choice, faced by the entity, so that it would be later possible to evaluate the gains and losses from the given alternatives. It performs a kind of introductory analysis to ensure that only simplified data would be entering into the next phase. In the second phase, the entity already considers all alternatives and tries to choose the one with the highest value. According to both authors, at this point the value function is applied, not the function of expected utility.

Kahneman and Tversky (Tversky and Kahneman, 1992) characterize the value function in detail in their paper. The utility is influenced by changes in wealth, not by its absolute level. The authors liken this to the properties of the human sensory perception. People respond more to changes in light, temperature, etc. and compare them to the previous state or the state to which they are accustomed. This is a reference point defined by the past and present experience or the expectations based on them. A thing possessing a certain temperature can, therefore, be perceived as hot or cold according to the experience of the given subject/entity, thus their reference point. According to the authors, the same is true for wealth, health, prestige, etc. A certain level of wealth may represent great wealth for one person but poverty for another person (Figure 2). 


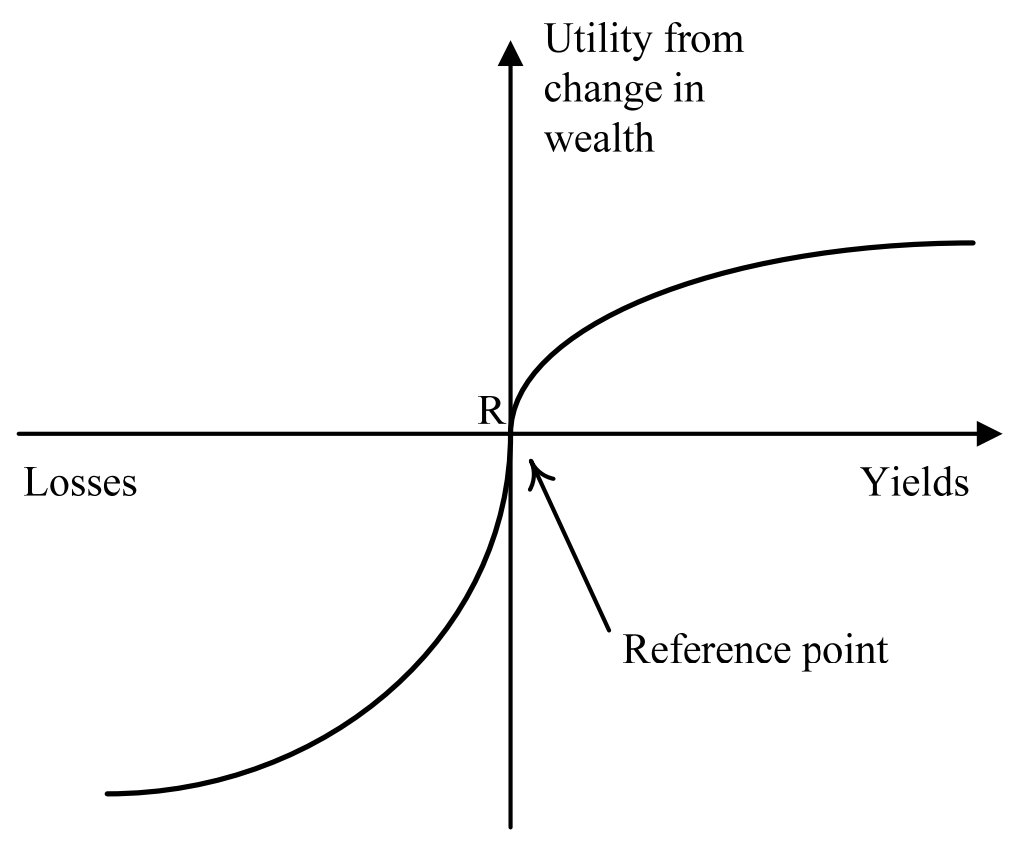

Figure 2. Kahneman's value function (Tversky and Kahneman, 1979)

The level of utility should therefore be determined by two variables. These are:

1) the reference point

2) the magnitude of the change and whether it is positive or negative in relation to the reference point

The value function by Kahneman and Tversky has the following basic features:

1) It is determined by the deviation from the reference point.

2) It is concave in the gain region and convex in losses. The break point is in the reference point.

3) The slope of the value function is $2-2.5$ times steeper in losses. This means that entities evaluate the pain of losing as $2-2.5$ times more intensely than the pleasure of gain, which is in absolute value of the same size, as has been found through empirical research.

4) It expresses a decreasing sensitivity to changes in the subjective evaluation of the changes in assets. Kahneman (Kahneman, 2012) puts it this way: "When you light up a dim light in a dark room, it has a significant effect. The same increase in the amount of light in a brightly lit room is almost unnoticed. Similarly, the difference between $\$ 900$ and $\$ 1000$ is much less than the difference between 100 dollars and 200 dollars."

In the prospect theory the level of the utility is modified by the decision-making weight. Kahneman and Tversky created a four-component model of preferences. It is based on two propositions. People appreciate gains and losses more than the absolute value of the assets and the decision weights are not identical with the probability of the results.

When there is a high probability of achieving high profits, the certainty effect is manifested. People have an aversion towards risk, when they are considering alternatives with a high probability of profit. They prefer to accept less than the expected value of a risky game. The fear of disappointment appears. This has already been described by D. Bernoulli.

If there is a low probability of achieving high profits, the effect of possibilities is manifested. People tend to take risks, even if the probability of winning, for example when purchasing a lottery ticket, is very small. It is manifested by an overestimation of low probabilities from which also stems the popularity of lotteries, Sportka etc.

If there is a low probability of large losses, people are willing to pay for insurance against the loss more than matches the expected value of risky alternatives that are not too likely. In this case aversion to a risk is 
manifested as a fear of large losses.

By contrast, if there is a high probability of large losses, it is manifested by tendency to seek risk. Kahneman cites two reasons for this effect (Kahneman, 2012). The reaction to the loss of $\$ 900$ is greater than a reaction to a $90 \%$ probability of losing $\$ 1000$ - a certain loss causes greater aversion. However, the second reason acts more strongly - the decision-making weight, which corresponds to a probability of $90 \%$, is only 71 , therefore it is relatively lower.

The entity therefore considers a choice between a certain loss and a risky game with a high probability of a larger loss. Thus the entity has a greater aversion to a certain loss but the certainty effect reduces an aversion to a more risky game. Both effects thus act in a mirror-reversed fashion, compared with the first case, where, by contrast, the attractiveness of a certain income is increasing and the attractiveness of high payouts is decreasing, even if there is only a small probability of loss.

As stated by Kahneman: "When we checked our choices of unfavorable alternatives, we realized that we have in losses an equally strong tendency to take risks, as we have in profits a tendency to reject risk" (Kahneman, 2012).

In the case of deciding on alternatives with a high probability of profit or loss, the shape of Kahneman's value function as well as decision weights, act in the same direction. In the case of deciding on alternatives with a low probability of profit or loss, both factors act in the opposite direction. People are willing to take risks in the case of gains and they are careful in the case of losses.

\subsection{Deviations from Normal Rationality in Prospect Theory (Summary)}

In principle, we can divide the differences in the entity's reasoning into cognitive and emotional. The cognitive ones involve the collection, analysis and use of information, the emotional ones concern the role of feelings, attitudes, intuition and embedded preferences in the process of decision-making and choice of subjects.

The first group includes large self-confidence and an illusion of control, overestimation of the significance of certain events, heuristics, accessibility, non-representativeness, anchoring, selective memory, framing and non-linear appreciation of probabilities.

The second group includes aversion to risks, understood here as an asymmetry in evaluation of gains and losses and the sensitivity to loss, recovery knowledge and reproach, which is later developed by the theory of remorse, distortion of reality and imperfect self-control.

M. Rabin, behavioral economist, has mathematically proved in his paper (Rabin, 2000) that the aversion to loss cannot be explained only on the basis of expected utility theory.

Rabin states that anyone who refuses to play a game involving risk and playing for small amounts, will exhibit a strong aversion towards taking risks in games which play for large sums. Most entities will refuse a game, which has a fifty percent probability of gaining $\$ 50$ and losing $\$ 100$. Rabin proves that according to the theory of expected utility such a entity should also reject a game, which has a fifty percent chance to gain $\$ 20,000$ and lose $\$ 200$. However, only few would apparently refuse such a game.

Both theories are primarily concerned with how the entities choose between alternatives. The main differences between both approaches were summarized by C. Starmer (Starmer, 2000):

1) In the theory of expected utility the entities make a choice on the basis of expected utility in absolute terms, in the prospect theory they make decisions mainly according to the change in wealth relative to a reference point.

2) In the theory of expected utility, the behavior of entities is basically characterized by the same risk aversion according to the given expected utility function, if we assume its concave shape, in the prospect theory they behave with a greater risk aversion if they perceive the change in wealth as a gain, but they are willing to risk more, if they perceive it as a loss. Thus the entities perceive equally large losses more intensely than gains. This is expressed by the Kahneman's function of value. Kahneman and Tversky use the term "loss aversion" to explain this asymmetry. The entities also perceive differently the clusters of losses and clusters of gains.

3) In the expected utility theory the objective probabilities are used to express risk, in the prospect theory within the framework of descriptive theory of preferences the weighted probabilities are used, that is, they are modified by subjective scales that explain, for example, overestimation of small probabilities or the certainty effect. 
4) In the prospect theory the framing effects and heuristics are manifested in the decision making of entities, but in the expected utility theory they are not.

Other differences include, for example, that, according to Thaler, people do not ignore sunk costs (Thaler, 1980), the presumption of wealth substitution is not valid, or the concept of experienced utility, these differences are not investigated by this paper, but the concept of behavioral economics is much broader.

\section{Conclusions}

In general, D. Kahneman and A. Tversky are considered to be the founders of behavioral economics. The predecessor of their concept was H. Simon, who had previously reached similar conclusions, but created only a theoretical mathematical model without experiments

According to Simon's concept of bounded rationality, an entity makes a decision on the basis of a set of available relevant information and, unlike the neoclassical approach, does not have perfect knowledge of alternatives. The entity assumes imperfect (incomplete) knowledge, because getting perfect knowledge would be too costly. Once it reaches the aspiration level, the decision-making process is terminated and an appropriate alternative is chosen. The strategy of achieving a satisfactory (not optimal) result simplifies the process of finding solutions it burdens the entity far less. Phenomena that were previously regarded as mistakes or distortions began to be seen as manifestations of adaptive rationality under specific conditions.

A contribution was provided by the performance of countless experiments to support the theoretical concepts of heuristics, framing and others. Behavioral theory presumes cognitive imperfection in decision making and subsequent behavior of the entity, which makes the presence of systematic errors in this process possible.

The prospect theory is an alternative to the neoclassical models of expected utility, etc. The most important representatives of it were D. Kahneman and A. Tversky. It is based on a psychological approach to the issue being examined, but it uses similar analytical tools as the model of expected utility. However, it has several features that set it apart from the theory. The most important ones are the anchoring heuristics, point of reference, aversion to loss and transformation of probabilities.

Thus, economic decisions made under the conditions of risk and uncertainty may differ from the prognosis of the expected utility theory. The prospect theory explains a number of phenomena that are inconsistent with the expected utility model. D. Kahneman and A. Tversky have become the chief advocates of the behavioral theory in economic thinking which is used, besides other things, for the analysis of the assets market. However, their observations are also important in other areas of human economic activity.

\section{Acknowledgments}

The paper was prepared with the support of the Czech University of Life Sciences Prague (Project No. 20141023 - The Validation of the Sweezy model of Price Competition in Oligopolistic Markets with Private Label Food).

\section{References}

Blaug, M. (1992). The methodology of economics: Or how economists explain (2nd ed). Cambridge: Cambridge University Press. ISBN 978-05-214-3678-6. http://dx.doi.org/10.1017/CBO9780511528224

Colander, D. (2000). The Death of Neoclassical Economics. Journal of the History of Economic Thought, 22(2), 127-143. ISSN 1053-8372. http://dx.doi.org/10.1080/10427710050025330 .

Edgeworth, F. (1967). Mathematical Psychics: An essay on the application of mathematics to the moral science. New York: Augustus M. Kelly Publisher, p. 152. ISBN 978-11-130-2058-1.

Kahneman, D. (2012). Myšlení rychlé a pomalé. Brno: Jan Melvil Publishing. ISBN 978-80-872-7042-4.

Kahneman, D., \& Tversky, A. (1974). Judgement Under Uncertainty: Heuristics and Biases. Science, New Series, 185(4157), 1124-1131. ISSN 0036-8075.

Kahneman, D., \& Tversky, A. (1981). The Framing of Decisions and the Psychology of Choice. Science, New Series, 211(4481), 453-458. ISSN 0036-8075.

Kahneman, D., \& Tversky, A. (1986). Rational Choice and the Framing of Decisions. The Journal of Business, 59(4), 251-278. ISSN 0021-9398.

Rabin, M. (2000). Risk Aversion and Expected-Utility Theory: A Calibration Theorem“. Econometrica, 68(5), 1281-1292. ISSN 0012-9682. http://dx.doi.org/10.1111/1468-0262.00158

Schumpeter, J. (1994). History of Economic Analysis. London: Routledge. ISBN 978-04-151-0888-1.

Simon, H. (1955). Behavioral Model of Rational Choice. The Quarterly Journal of Economics, 69(1), 99-118. 
ISSN 0033-5533. http://dx.doi.org/10.2307/1884852

Simon, H. (1983). Reason in Human Affairs. Stanford: Stanford University Press. ISBN 978-08-047-1179-1.

Simon, H. (1996). The Science of the Artificial. London: Massachusetts Institute of Technology Press.

Smith, A. (2005). Teorie mravních citů. Praha: Liberální institute. ISBN 80-86389-15-4.

Starmer, C. (2000). Developments in Non-expected Utility Theory: The Hunt For A Descriptive Theory of Choice Under Risk. Journal of Economic Literature, 38(2), 332-382. ISSN 0022-0515. http://dx.doi.org/10.1257/jel.38.2.332

Thaler, R. (1980). Toward a Positive Theory of Consumer Choice. Journal of Economic Behavior and Organization, 1(1), 39-60. ISSN 0167-2681. http://dx.doi.org/10.1016/0167-2681(80)90051-7

Tversky, A., \& Kahneman, D. (1979). Prospect Theory: An Analysis of Decision Under Risk. Econometrica, 47(2), 263-291. ISSN 0012-9682.

Tversky, A., \& Kahneman, D. (1992). Advances in Prospect Theory: Cumulative Representation of Uncertainty. Journal of Risk and Uncertainty, 5(4), 297-323. ISSN 0895-5646. http://dx.doi.org/10.1007/BF00122574

\section{Copyrights}

Copyright for this article is retained by the author(s), with first publication rights granted to the journal.

This is an open-access article distributed under the terms and conditions of the Creative Commons Attribution license (http://creativecommons.org/licenses/by/3.0/). 